\title{
Biphasic Synovial Sarcoma of the Hypopharynx with Vertebral Metastasis: A Rare and Aggressive Entity
}

\author{
${ }^{1}$ Anju Chauhan, ${ }^{2}$ Vikas Malhotra, ${ }^{3}$ Samuel Rajan, ${ }^{4}$ Komal Lamba, ${ }^{5}$ Nidhi Mahajan
}

\begin{abstract}
Introduction: Synovial sarcoma is a malignant tumor which is mesenchymal in nature and most commonly involves the joints of the lower limbs. Sarcomas of the head and neck region are very rare, accounting for less than $1 \%$ of all neoplasms of the head and neck.
\end{abstract}

Case report: A 60-year-old male presented to ear, nose, and throat (ENT) emergency with complaints of change in voice and difficulty in swallowing since 10 days.

On indirect laryngoscopic examination, there was a reddish smooth mass seen involving the left lateral pharyngeal wall and obscuring left pyriform sinus. A contrast-enhanced computed tomography (CECT) scan of the neck was done, which revealed a well-defined heterogeneously enhancing soft tissue lesion in the left pyriform sinus. On direct endoscopic assessment, a friable reddish mass was seen in the left pyriform sinus, which was excised and sent for biopsy.

Pathological examination showed a biphasic lesion comprising of epithelial component arranged in nests and stromal component arranged in spindled out cells. Immunohistochemistry was positive for vimentin and cytokeratin suggestive of biphasic synovial sarcoma. Before definitive management as a part of metastatic work-up, patient underwent magnetic resonance imaging (MRI) of neck and spine, which revealed a metastatic lesion in cervical spine. Subsequently, the patient was referred to radiation oncology for radiotherapy.

Conclusion: Synovial sarcoma is a rare malignant tumor whose management is mainly surgical resection with postoperative radiotherapy for residual or recurrent disease.

We have presented this case on account of its rarity of occurrence and its aggressive nature, as it presented with vertebral metastasis which further emphasizes the need for a complete metastatic work-up for cases before being planned for surgery.

Keywords: Pyriform sinus, Radiotherapy, Synovial sarcoma.

How to cite this article: Chauhan A, Malhotra V, Rajan S, Lamba K, Mahajan N. Biphasic Synovial Sarcoma of the Hypopharynx with Vertebral Metastasis: A Rare and Aggressive Entity. Int J Otorhinolaryngol Clin 2018;10(2):76-79.

\footnotetext{
${ }^{1,3}$ Senior Resident, ${ }^{2}$ Professor, ${ }^{4}$ Junior Resident, ${ }^{5}$ Assistant Professor

${ }^{1-4}$ Department of ENT, Maulana Azad Medical College, Gurugram Haryana, India

${ }^{5}$ Department of Pathology, Maulana Azad Medical College Delhi, India

Corresponding Author: Anju Chauhan, Senior Resident Department of ENT, Maulana Azad Medical College, Gurugram Haryana, India, e-mail: anju2716@gmail.com
}

\section{Source of support: None}

Conflict of interest: None

\section{INTRODUCTION}

Synovial sarcoma is a rare malignant mesenchymal tumor that originates in the joint capsules and tendon sheaths of lower limbs. About 1 to 3 individuals in a million people are diagnosed with this disease each year, and thus, it is one of the very rare tumors. It has slight preponderance for males, with 12 male patients for every 10 female patients.

Jernstrom ${ }^{1}$ was the first one to document a case of synovial sarcoma in the head and neck region and since then, only about 90 such cases have been described. Two different types have been described, namely biphasic type composed of both epithelial cells and spindle cells and monophasic type where a single cellular component is dominant. Immunohistochemistry plays a very important role in the diagnosis of this rare entity.

We hereby report a case of biphasic synovial sarcoma of the hypopharynx with metastasis to vertebral bodies which was managed by excision biopsy followed by radiotherapy.

\section{CASE REPORT}

A 60-year-old male presented to the ENT emergency with complaints of change in voice and difficulty in swallowing since 10 days. The change in voice was acute in onset, muffled in character with no aggravating or relieving factors.

There was no history of voice abuse or preceding upper respiratory tract infection. The dysphagia was also acute in onset, progressive, more to solids than liquids not associated with odynophagia. There was no history of respiratory distress, cough, fever, chest pain, or hemoptysis.

On indirect laryngoscopic examination, there was a smooth, round, pale cystic swelling seen in the left vallecula and a reddish smooth mass seen below it involving the left lateral pharyngeal wall and obscuring left pyriform sinus. The bilateral true vocal cords were mobile and rest of the larynx showed no abnormality. Neck examination revealed no palpable neck nodes. 


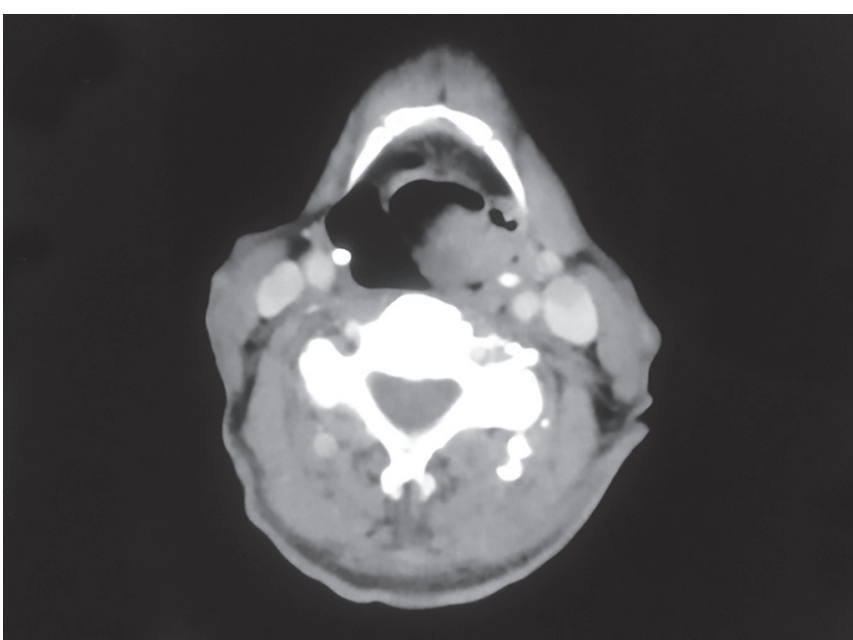

Fig. 1: Computed tomography scan showing soft tissue lesion in left pyriform sinus



Fig. 3: Photomicrograph showing markedly cellular biphasic tumor composed of epithelial and spindle cell elements

A CECT scan of the neck was done which revealed a well-defined heterogeneously enhancing soft tissue lesion measuring $2.5 \times 2.5 \mathrm{~cm}$ in the left pyriform sinus (Fig. 1). There was also another well-defined hypodense lesion measuring $1.2 \times 1.9 \mathrm{~cm}$ of near fluid attenuation in the left vallecula, suggestive of a vallecular cyst. Patient was taken up for direct endoscopic assessment and biopsy.

Boyle Davis mouth gag was used along with $0^{\circ}$ endoscope with camera and monitor to assess the lesion. Vallecular cyst was removed in toto. Next, the mass in the pyriform sinus was assessed. It was found to be attached to the lateral pharyngeal wall with a narrow base and filling up the pyriform sinus (Fig. 2). It was friable and bled on biopsy. The mass was removed by dividing the attachment as an excision biopsy which was then sent for histopathological analysis.

Pathological examination was suggestive of a biphasic lesion comprising of epithelial component arranged in

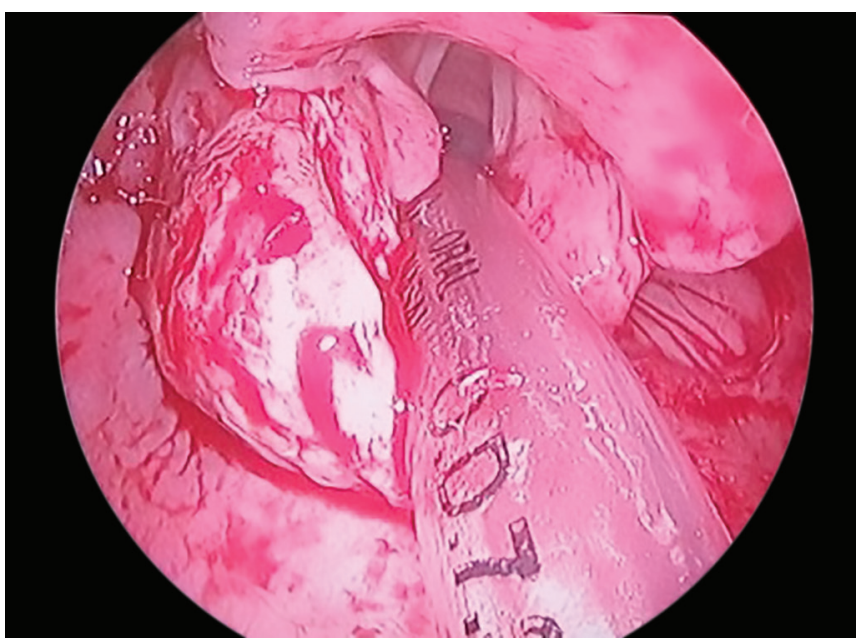

Fig. 2: Intraoperative endoscopic appearance of mass in left pyriform sinus

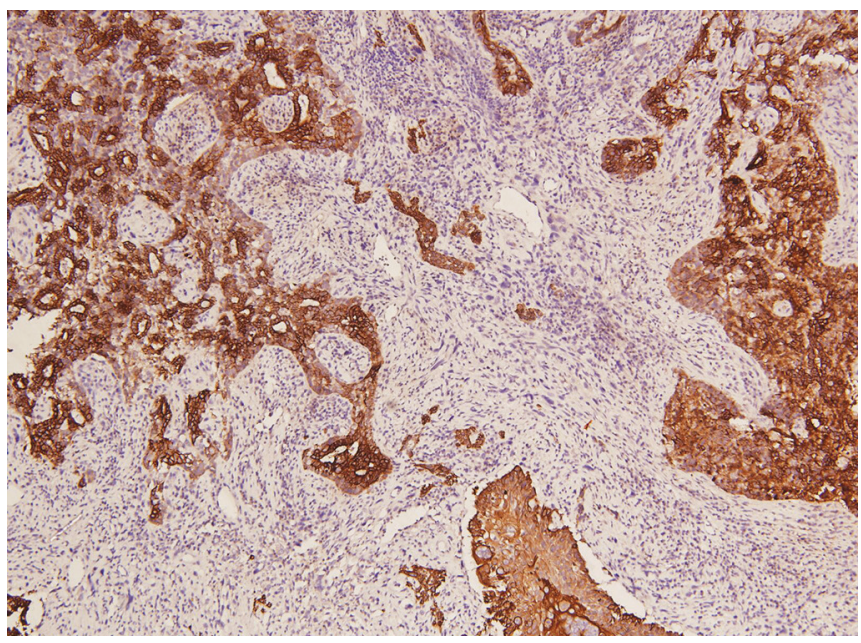

Fig. 4: Immunohistochemistry showing strong cytokeratin reactivity in the epithelial component

nests and stromal component arranged in spindled out cells (Fig. 3). Immunohistochemistry was positive for vimentin and cytokeratin, suggestive of biphasic synovial sarcoma (Fig. 4). Patient underwent metastatic work-up wherein MRI neck with chest was done which revealed metastasis to cervical spine at level C6 (Fig. 5). The patient has been referred to the Radiation Oncology Department for radiotherapy.

\section{DISCUSSION}

Synovial sarcoma is a rare neoplasm which accounts for 8 to $10 \%$ of all soft tissue sarcoma, and out of these, around 3 to $10 \%$ of sarcomas occur in the head and neck. ${ }^{2-4}$ These tumors can have varying locations in the head and neck extending from base of skull to clavicle, such as prevertebral space, retropharyngeal space, along anterior border of sternocleidomastoid, oropharynx, and even in larynx. ${ }^{5,6}$ This type of tumor appears as an 


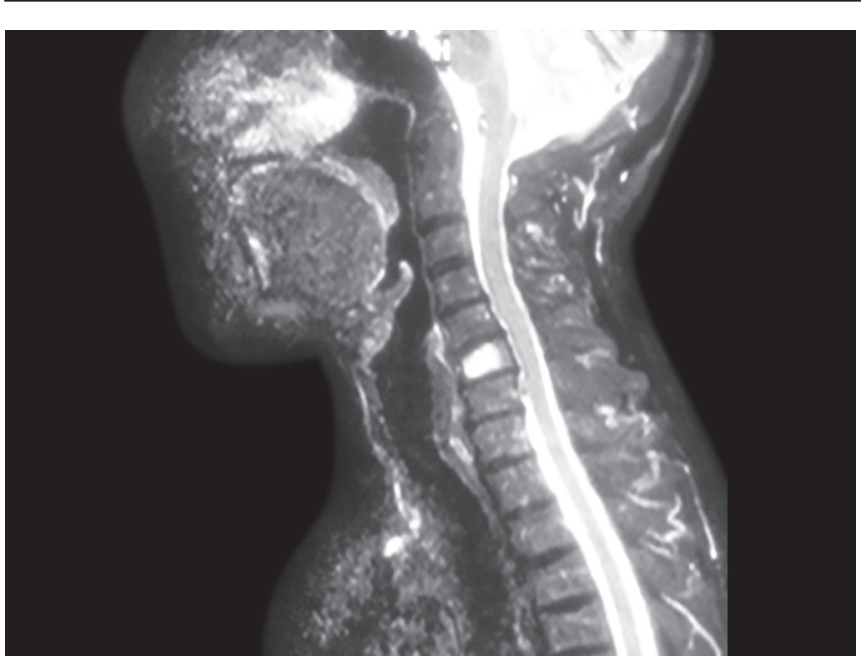

Fig. 5: Magnetic resonance imaging neck showing metastasis at level $\mathrm{C} 6$ vertebrae

asymptomatic swelling which slowly increases in size and causing symptoms due to obstruction/pressure on surrounding areas. ${ }^{7}$

In the head and neck region, it usually presents with symptoms of worsening dysphagia, earache, dyspnea, or neck swelling. Histologically, there are two subtypes: biphasic and monophasic types. The classic features include spindle cells with vesicular, plump, and overlapping nuclei with hemangiopericytic vessels.

The biphasic type consists of a mixture of glandular structures lined by cuboidal or columnar epithelium surrounded by a sarcomatous stroma. Its other features include presence of mast cells and calcification with or without ossification. Monophasic type consists of single cellular type, i.e., epithelioid or spindle cells both staining positive for cytokeratin and epithelial membrane antigen.

The difference between epithelioid and spindle cell component is done by vimentin, a mesenchymal marker. Vimentin stains positive with spindle cells and negative with epithelioid type. The CT and MRI are nonspecific in diagnosis, but are useful in planning the treatment strategy.

In 30 to $60 \%$ of synovial sarcoma cases, intralesional calcifications have been found at CT examination which, when present, are to be considered a positive prognostic factor. ${ }^{8}$ The prognostic factors associated with it include age, tumor size, mean mitotic index, biphasic type having a better prognosis to monophasic type, and margins of resection at surgery. ${ }^{9,10} \mathrm{New}$ studies have indicated several other possible prognostic parameters. A Ki-67 index of 10\% or more was considered highly proliferative. ${ }^{11}$

The mainstay of management of head and neck synovial sarcomas is resection with adequate margins, since margin of resection is one of the most important prognostic factors for survival. ${ }^{4,12}$ The possibility of local recurrence is around 30 to $40 \%$ with around $50 \%$ chances of distant metastasis, especially in cases with higher grade of tumor and inadequate tumor clearance in surgery.

The most frequent sites of metastasis is the lung ( $49 \%)$ followed by skeleton (24\%), liver (14\%), and brain (11\%). ${ }^{13}$ The primary disease presenting with vertebral metastasis is extremely rare as seen in this case. Multimodality treatment in the form of surgery with 1 to $3 \mathrm{~cm}$ margin followed by postoperative external beam radiotherapy particularly if margins are close to critical neurovascular structures is the mainstay of management. Local radiotherapy dose is 40 to $60 \mathrm{~Gy}$. Intensity modulated radiotherapy has also been proposed. ${ }^{14}$

Although radiotherapy does not improve long-term survival, it helps in reducing the incidence of locoregional recurrence. ${ }^{15}$ The role of chemotherapy is controversial. Despite relatively slow growth, long-term survival for synovial sarcomas from anywhere, including the head and neck, is not good. ${ }^{3}$

\section{CONCLUSION}

Synovial sarcoma is a rare malignant tumor whose treatment is mainly surgical resection with postoperative radiotherapy for residual or recurrent disease. The treatment of most hypopharyngeal malignancies is usually laryngopharyngectomy; however, it can be modified in cases of synovial sarcoma to wide local excision with adequate margins.

In these cases, most important are the surgical margin's microscopic control and lack of lymphatic metastasis. We have presented this case on account of its rarity of occurrence and its aggressive nature, as it presented with vertebral metastasis which further emphasizes the need for a complete metastatic work-up for cases before being planned for surgery.

\section{REFERENCES}

1. Jernstrom P. Synovial sarcoma of the pharynx: report of a case. Am J Clin Pathol 1954;24:957-961.

2. Ramamurthy L, Nassar WY, Hasleton PS, Gattamaneni HR, Orton CI. Synovial sarcoma of the pharynx. J Laryngol Otol 1995 Dec;109(12):1207-1210.

3. Carrillo R, Rodriguez-Peralto JL, Batsakis JG. Synovial sarcomas of the head and neck. Ann Otol Rhinol Laryngol 1992 Apr;101(4):367-370.

4. Betal D, Babu R, Mehmet V. Monophasic synovial sarcoma of the pharynx: a case report. Int Semin Surg Oncol 2009 Mar 31;6:9.

5. Bukachevsky RP, Pincus RL, Shechtman FG, Sarti E, Chodosh P. Synovial sarcoma of the head and neck. Head Neck 1992;14(1):44-48.

6. Shaariyah MM, Mazita A, Masaany M, Razif MY, Isa MR, Asma A. Synovial sarcoma: a rare presentation of parapharyngeal mass. Chin J Cancer 2010 Jun;29(6):631-633.

7. Saydam L, Kizilay A, Kalcioglu MT, Mizrak B, Bulut F. Synovial sarcoma of the pharynx: a case report. Ear Nose Throat J 2002 Jan;81(1):36-39. 
8. Artico R, Bison E, Brotto M. Monophasic synovial sarcoma of hypopharynx. Acta Otolaryngol Ital 2004 Feb;24(1): 33-36.

9. Skytting B. Synovial sarcoma: a Scandinavian Sarcoma Group Project. Acta Orthop Scand Suppl 2000 Apr;291:1-28.

10. Weiss SW, Goldblum JR. Malignant soft tissue tumors of uncertain type. In: Enzinger and Weiss's Soft Tissue Tumors. 4th ed. St. Louis: Mosby; 2001.

11. Skytting BT, Bauer HC, Perfekt R, Nilsson G, Larsson O. Ki-67 is strongly prognostic in synovial sarcoma; analysis based on 86 patients from the Scandinavian Sarcoma Group Register. Br J Cancer 1999 Aug;80(11):1809-1814.
12. Lee N, Shin E. Treatment outcomes for patients with synovial sarcoma of the head and neck. Expert Rev Anticancer Ther 2008 Mar;8(3):371-373.

13. Devis RK, Wana M. Soft tissue sarcomas of head and neck. In: Textbook of uncommon cancers. St. Louis; 1988, Ch. 53, pp. 1007-1017.

14. Lockey MW. Rare tumors of the ear, nose and throat: synovial sarcoma of the head and neck. South Med J 1976 Mar;69(3):316-320.

15. Amble FR, Olsen KD, Nascimento AG, Foote RL. Head and neck synovial cell sarcoma. Otolaryngol Head Neck Surg 1992 Nov;107(5):631-637. 